\title{
SIMULATION OF TEMPERATURE EVOLUTION OF CORK COMPOSITES DURING MOULDING PROCESS
}

\author{
Lopes, H. ; Silva, S. P. .* \& Machado, J.* \\ *University of Minho, MEtRICs Research Center, Campus of Azurém, 4800-058 Guimarães, Portugal \\ ** Amorim Cork Composites, Rua de Meladas, 260, 4535-186 Mozelos VFR, Portugal \\ E-Mail: id7466@alunos.uminho.pt
}

\begin{abstract}
Cork-based composites result from a combination of cork granules with different materials - like thermosets or thermoplastics - and its manufacture involves a thermal process. In order to simulate the manufacturing process, of these types of composites, a new methodology was applied. A material composed of cork and a thermoplastic served as a case study. A model for the prediction of a cork composite mixture properties and a simulation methodology were developed for studying the variation of temperature during the moulding process of cork composites. Density, thermal conductivity, and specific heat were determined based on the formulation of the composite and the properties of cork and the agglutinant agent. Numerical analyses were carried out and compared to experimental results obtained from a moulding process. Three types of simulations, according to the model of the chosen properties were developed using finite volume and finite element methods. In general, the results from the simulations were in good agreement with experimental results.

(Received in July 2020, accepted in November 2020. This paper was with the authors 1 month for 1 revision.)
\end{abstract}

Key Words: Temperature, Cork Composites, Thermal Conductivity, Specific Heat, Density

\section{INTRODUCTION}

Cork is a natural material obtained through the harvest of Quercus suber L. trees. This species of oak is predominant in montado, an ecosystem that exists in different areas in the west side of the Mediterranean Sea, particularly in Alentejo region of Portugal. Classified as a cellular material, cork presents low density, almost-zero Poisson's coefficient, good resilience, high energy absorption capacity, among other properties that allow its application in several fields [1]. The main productive activity of the cork industry is the production of stoppers that creates many remains that are not reintroduced in this process. The surplus of raw material can be applied mainly in the agglomerates and composites manufacturing, increasing its value [2].

The production of cork composites involves diverse aspects that must be considered in order to achieve the pretended performance of the material. Nowadays, these kinds of composites are used in many industries like automobile and aerospace, military, shoe, and construction [3]. The raw material used in the composite manufacturing is cork granules, the result of trituration of cork wastes from stoppers production, virgin cork and low-quality cork. The manufacturing of the composites consists, most of the times, in the junction of cork granules with agglutinant products, like resins and other additives, through the combination of high temperature and pressure [3].

There are research works related to the application of new products in the development of cork composites. One of the fields with great potential is the introduction of thermoplastic as a binding agent. The use of this kind of raw materials can reduce the solvent existence and other problems involving toxicity, that are common with resins used in the agglomerates production $[3,4]$.

One of the manufacturing techniques consists in placing the material mixture inside a rectangular or cylindrical mould. The first step of the process is related to the mixture of raw materials. After weighing each component, according to the imposed formulation, they are 
introduced in a mixer to achieve a homogeneous mixture. The material is then poured into the mould and compressed until its final thickness. The mould is closed and placed inside a heating chamber to allow the agglomeration of the mixture components, due to the action of a resin thermoset or due to the melting of a thermoplastic. The processing time may vary between four and twenty-two hours with temperatures reaching $120^{\circ} \mathrm{C}$ [3]. After a certain period of time, the mould is withdrawn from the heating chamber and placed at ambient temperature to be cooled before the material be removed from the mould. The blocks can be used as a raw material in other manufacturing processes in bulk or laminated form [3]. Besides compression moulding, other manufacturing processes can be applied for producing cork composites such as injection moulding and extrusion [5].

The technique of modelling and numerical simulation has been applied in the study of manufacturing processes of different types of materials [6-13]. The principal aim of these works is studying the allowance of using new tools that can help in the optimization of processing parameters to a specific material. The wood agglomerates are probably one of the areas with more knowledge about this thematic [7, 8]. Besides wood agglomerates, wood plastic composites (WPC) and other composites were the object of study by other researchers [6, 9, 12]. Regarding composites, one factor to add to the development time of new materials is the diversity of combinations between variables related to its composition - like matrix, fillers and other additives. As it influences the final mechanical properties [14], it can be very timeconsuming reach optimal processing conditions for each combination considered. Thus, not only the application of simulation tools is expected to result in an increased performance of new materials but also it can be used speed up the development time.

The aim of this study is to determine the temperature evolution of a cork composite material during the manufacturing process. This information could be used for optimizing process variables related to moulding process of cork composites like the temperature imposed in the heating chamber, the time spent inside the heating chamber, the amount of time necessary to cool down the mould and the material formulation (quantities of each component in the mixture). In the case study presented, all regions of the mixture must reach a temperature equal to or above the melting temperature of the thermoplastic material, in order to achieve a homogenous final product. This paper shows the implementation of a model to predict the properties of a mixture used to make a cork composite block and the simulations of temperature profiles at the centre of the block during the moulding process. The present study was developed in three distinct steps: characterization and implementation of properties models, numerical analysis and validation.

In order to achieve the main goals of this paper, it is organized as follows: chapter 2 presents the formulation of the problem and, also, the main working hypotheses; chapter 3 introduces the methods used to determine materials properties; chapter 4 presents the experimental setup used to monitor the temperature evolution during heating process; chapter 5 focus on the numerical analysis and obtained results; and chapter 6 presents the conclusions of the study.

\section{PROBLEM FORMULATION}

The development of cork composites requires a heating process. In order to simulate the moulding process, a mathematical description of the problem is presented including its assumptions, as well as the main idea behind the determination of mixture properties.

\subsection{Assumptions, governing equation and boundary conditions}

The presented model results from a first analysis of the manufacturing process. A schematic of the problem at study is presented in Fig. 1. For the case of composite cork blocks processing, 
the main physical phenomena, that is occurring, is transient heat transfer, whose governing equation is presented in Eq. (1).

$$
\rho c_{p} \frac{\partial T}{\partial t}=\left(k_{z} \frac{\partial T^{2}}{\partial^{2} z}\right)
$$

where $T$ is temperature, $t$ is time, $\rho$ is density, $c_{p}$ is specific heat, $k_{z}$ is thermal conductivity and $z$ indicates thickness direction. It was also considered the temperature influence on the thermal properties of the materials namely the thermal conductivity and specific heat.

During model development some considerations were made that include the following topics:

- Unidimensional model in the thickness direction;

- The flow of the resin/thermoplastic inside the mould is neglected;

- Only heat transfer by conduction was considered;

- Moisture content and water phase are not included in this model;

- The density of the compacted material remains the same throughout the process;

- The material was considered homogenous (the temperature in the cork particle is the same as the resin at any time);

- No deformation occurs during the compressing moulding process;

- No thermal resistance considered between the mould surfaces and the mixture.

In this study, it was considered symmetry in terms of properties and temperatures gradients at half of the thickness, to reduce computation time during problem-solving. The other boundary condition consists of convection at the mould surface. The representation of the problem domain is also depicted in Fig. 1.

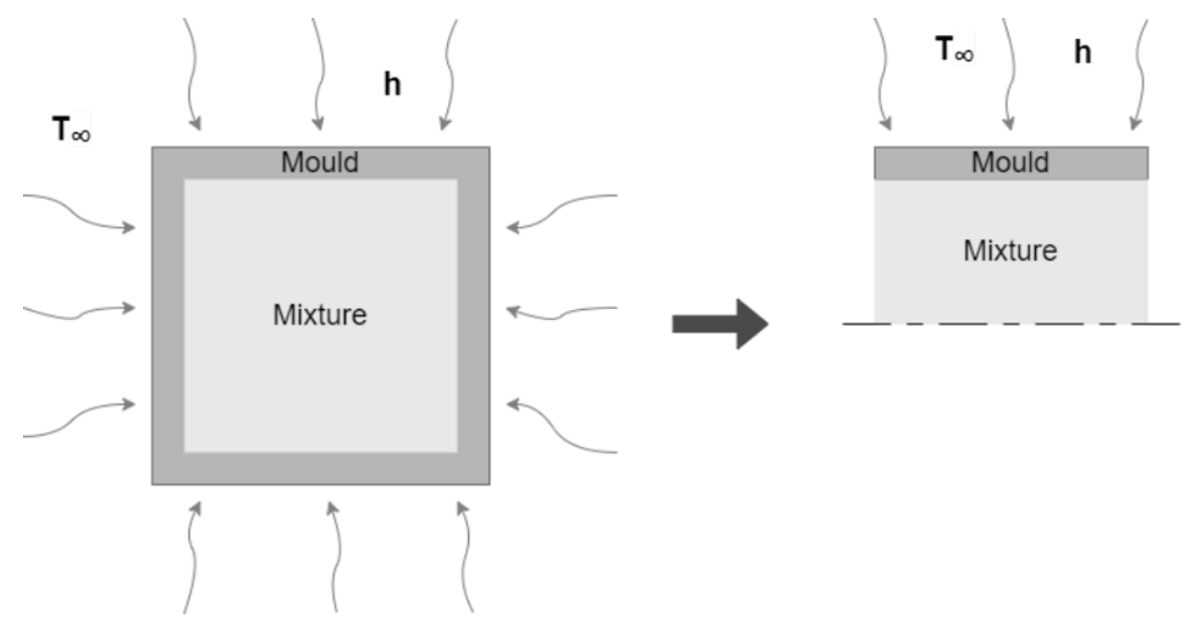

Figure 1: Schematic of the block moulding heating process and considered problem domain with convective heat and symmetry boundaries.

\subsection{Modelling of thermal and physical properties}

The input properties for the mixture were modelled according to the composition of the cork composites. A model was developed to compute volume and mass fractions of each component of the mixture. The developed model considers cork as a combination of two different materials in a solid and a gaseous phase. The solid phase corresponds to the cell walls material and the second one is considered as air. The volume and fractions of each component of the mixture resin, cork cell walls, and air - are calculated before and after compaction occurs, only considering the exit of the gaseous phase in the material (Fig. 2). 


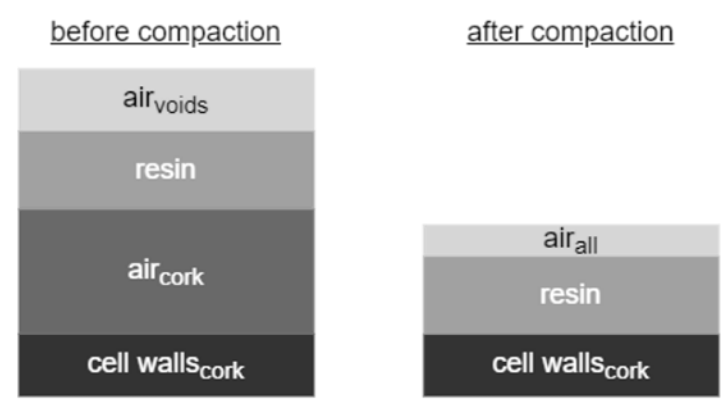

Figure 2: Schematic for the developed model.

\section{MATERIAL PROPERTIES}

In the characterization stage, materials were analysed to determine their thermal and physical properties. In terms of raw materials, if some of their properties were already described in the literature or determined by other means, that values were used during modelling and simulation stages. To determine the values of density, specific heat and thermal conductivity coefficients of the compacted mixture, the model presented in the previous section was applied.

\subsection{Density}

Due to the presence of bulk materials like cork or other types of polymers, it is necessary to evaluate two properties: the bulk and real densities. To determine the bulk density of the raw material, the weighing of the material within a known volume is used:

$$
\rho=\frac{m}{V}
$$

where $\rho$ is bulk density $\left[\mathrm{kg} / \mathrm{m}^{3}\right], m$ is mass $[\mathrm{kg}]$ and $V$ is volume $\left[\mathrm{m}^{3}\right]$. The density of the final product was also evaluated by the application of the previous equation.

To evaluate the real density a procedure based on the pycnometer method was implemented. The specific gravity of a sample is calculated by the following equation:

$$
d=\frac{M_{1}}{M_{1}+M_{2}-M_{3}}
$$

where $M_{1}$ is the mass of the sample, $M_{2}$ is the mass of the beaker filled with water and $M_{3}$ is the mass of the beaker filled with water and the sample.

In this method, to prevent the buoyancy of the cork granules, a beaker and two metallic nets - whose orifices had a smaller dimension than the sample granules - were used (Fig. 3). The specific gravity of the cork sample is calculated by the Eq. (3), but, in this case, it must be added the mass of the two nets to the mass of the beaker filled with water $\left(M_{2}\right)$ and the total set $\left(M_{3}\right)$. Another thing to consider, in the case of cork or other wood types, is that the measurement of the total set $\left(M_{3}\right)$ must be performed in a very short interval of time, in order to reduce the possible influence of water absorption, that can occur by water absorption by the samples.

As no variation of volume in the mixture occurs during the heating stage, it was considered that density is constant at any time of this process and dependent only of the volume fraction of each considered component:

$$
\rho=v_{r} \rho_{r}+v_{w_{c}} \rho_{w_{c}}+v_{a_{c}} \rho_{a_{c}}+v_{a} \rho_{a}
$$

where $v$ is the mass fraction of agglutinant $(r)$, cork cell walls $\left(w_{c}\right)$, cork gaseous phase $\left(a_{c}\right)$ and air in the mixture $(a)$. 


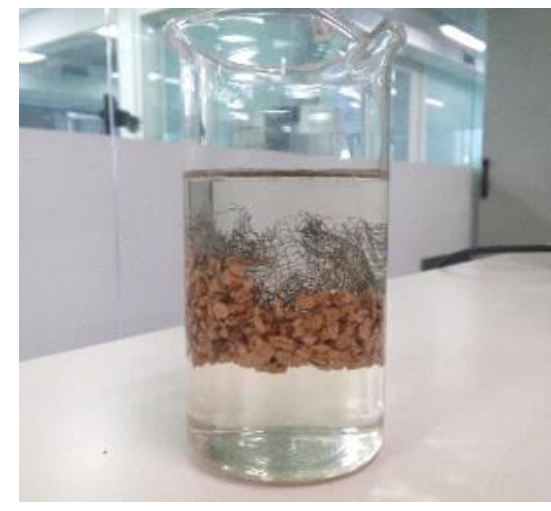

Figure 3: Metallic nets used for the determination of cork granules real density.

\subsection{Specific heat}

The specific heat of the mixture was determined based on the mass fraction of each component of the mixture: cork solid phase, air and thermoplastic, whose equations, considering or not temperature dependence, are presented in Eqs. (5) and (6).

$$
\begin{gathered}
c_{p}=m_{r} c_{p_{r}}+m_{w_{c}} c_{p_{w_{c}}}+m_{a_{c}} c_{p_{a_{c}}}+m_{a} c_{p_{a}} \\
c_{p}(T)=m_{r} c_{p_{r}}(T)+m_{w_{c}} c_{p_{w_{c}}}(T)+m_{a_{c}} c_{p_{a_{c}}}(T)+m_{a} c_{p_{a}}(T)
\end{gathered}
$$

where $m$ is the mass fraction of each component given by Eq. (7).

$$
m_{1}=\frac{v_{1} \rho_{1}}{v_{1} \rho_{1}+v_{2} \rho_{2}+\cdots+v_{n} \rho_{n}}
$$

where $1,2, \ldots, n$ corresponds to the component number present in the mixture.

It can also be considered in the model the effect of phase change on the thermoplastic specific heat [15]. The value of specific heat of thermoplastic is calculated according to the following equation:

$$
c_{p_{t}}=\left\{\begin{array}{c}
c_{p_{s}} \\
\frac{c_{p_{s}}+c_{p_{L}}}{2}+\frac{L}{c_{p_{L}}+T_{S}}
\end{array}\right.
$$

where $c_{p_{t}}$ is the specific heat of the thermoplastic $[\mathrm{J} / \mathrm{kg} \cdot \mathrm{K}], L$ is the latent heat of fusion $[\mathrm{J} / \mathrm{kg}]$ and $S$ and $L$ are subscripts for solid and liquid phase, respectively.

\subsection{Thermal conductivity}

Regarding the thermal conductivity coefficient determination, it was considered a combination of thermal resistances depicted in Fig. 4 correspondents to the three mixture components. This model is constituted by two arms, one of which has three thermal resistances in series (1) and another one where the same resistances are arranged in parallel (2). Once the heat flux through an association in series is equal to the one across every resistance, the equivalent thermal conduction coefficient is calculated by Eq. (9). For the association, in parallel, the value of the coefficient is determined by Eq. (10).

$$
\begin{gathered}
k_{s}=\left(\frac{v_{a}+v_{a_{c}}}{k_{a}}+\frac{v_{r}}{k_{r}}+\frac{v_{w_{c}}}{k_{w_{c}}}\right)^{-1} \\
k_{p}=\left(v_{a}+v_{a_{c}}\right) k_{a}+v_{r} k_{r}+v_{w_{c}} k_{w}
\end{gathered}
$$




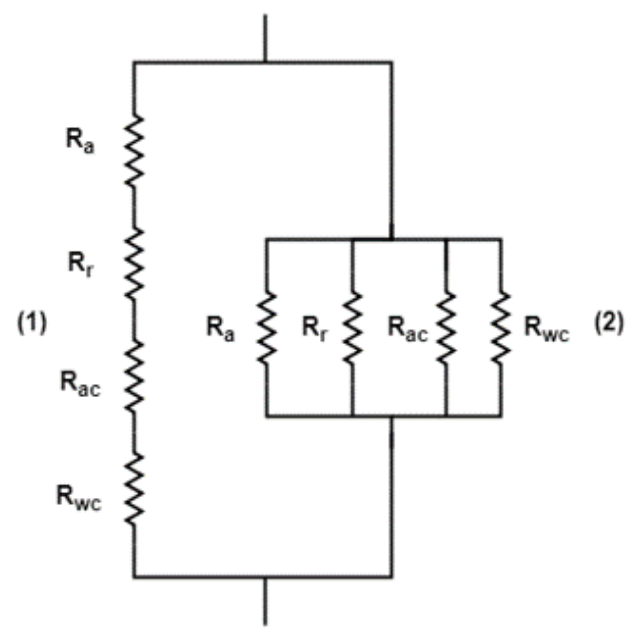

Figure 4: Thermal resistances model used to determine the thermal conductivity coefficient.

For this model, equal heat fluxes across each arm were considered, see Eq. (11). In some cases, it can also be considered the dependence of temperature on the value of the thermal conductivity coefficient. So, at each new value of temperature the thermal conductivity of the mixture is calculated according to Eq. (12).

$$
\begin{gathered}
k=\frac{k_{s}}{2}+\frac{k_{p}}{2} \\
k(T)=\frac{1}{2}\left[\frac{v_{a}+v_{a_{c}}}{k_{a}(T)}+\frac{v_{r}}{k_{r}(T)}+\frac{v_{w_{c}}}{k_{w_{c}}(T)}\right]^{-1}+\frac{1}{2}\left[\left(v_{a}+v_{a_{c}}\right) k_{a}(T)+v_{r} k_{r}(T)+v_{w_{c}} k_{w_{c}}(T)\right]
\end{gathered}
$$

The temperature dependence of the cork thermal conductivity coefficient of the cork was based on the Eurocode 5 [16]. It was assumed for cork the same linear dependence of wood between 20 and $200{ }^{\circ} \mathrm{C}$. Based on the literature value of thermal conductivity at ambient temperature $(0.045 \mathrm{~W} / \mathrm{m} \cdot \mathrm{K}$ [1] $)$ the temperature dependence of cork thermal conductivity coefficient was calculated by the following equation:

$$
k_{c}=1,67 \times 10^{-4} T+4,17 \times 10^{-2}
$$

The thermal conductivity of cork cell walls is determined based on a parallel association of a thermal resistance model of the two phases of cork:

$$
k_{w_{c}}(T)=\frac{k_{c}(T)-k_{a}(T)(1-x)}{x}
$$

where $x$ is equal to:

$$
x=\frac{k_{c}\left(20^{\circ} \mathrm{C}\right)-k_{a}\left(20^{\circ} \mathrm{C}\right)}{k_{w_{c}}\left(20^{\circ} \mathrm{C}\right)-k_{a}\left(20^{\circ} \mathrm{C}\right)}
$$

Based on the literature value for cork cell walls thermal conductivity at ambient temperature $(0.2 \mathrm{~W} / \mathrm{m} \cdot \mathrm{K}[1])$ the temperature dependence of cork cell walls was calculated as:

$$
k_{w}=0,001 T+0,1809
$$

\section{EXPERIMENTAL SETUP}

To evaluate the results provided by the numerical analysis, these were compared with experimental results. One block sample with dimensions $150 \times 150 \times 35 \mathrm{~mm}$ was made for this experiment. During the placement of the mixture in a mould, a thermocouple was positioned in the centre of the mixture block - the most critical region of the block (Fig. 5). The thermocouple was linked to a data acquisition system to register the evaluation of temperature during the 
heating process. The data obtained by the thermocouple was then compared with the simulation results to evaluate the validity of the developed model.

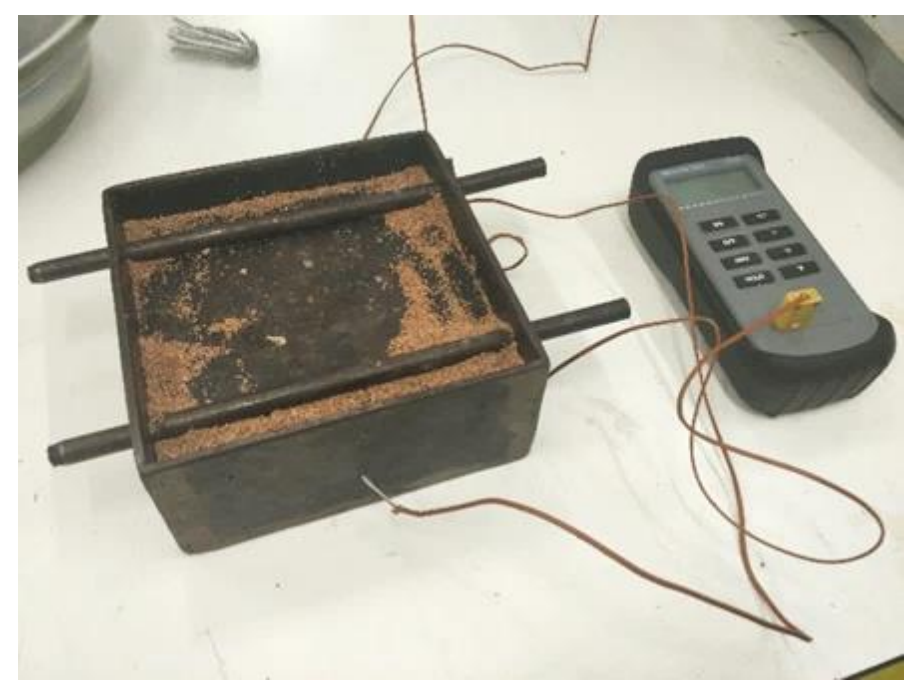

Figure 5: Thermocouple placed inside the cork composite block.

\section{NUMERICAL ANALYSIS}

Numerical analyses were divided into three categories. The first one considered the thermal properties - thermal conductivity coefficient and specific heat - independent of the values of temperature at each time and location. For this analysis, two different numerical methods were applied: finite volume method - employed in a MATLAB code - and finite element method using commercial software package Ansys Workbench (Transient Thermal module). The performance of the two methods was compared.

The second analysis category only considered the temperature dependence of the thermal conductivity coefficient. The specific heat value of the mixture was considered to be the same throughout the heating process. Like the first analysis, were employed the finite volume method - written a MATLAB code considering temperature dependence of thermal conductivity - and finite element method - using commercial software package Ansys Workbench (Transient Thermal module).

The third category considered the temperature dependence of the two thermal properties. In this case, only was applied the finite element analysis using Ansys Workbench (Transient Thermal module).

Analyses of sensibility regarding the mesh size and the time discretization were also conducted for all analyses.

\subsection{Inputs}

The first step of the numerical analyses consisted of predicting the mixture's physical and thermal properties based on the following inputs. The values presented in Table I were obtained using experimental data and values from the literature.

The results from the mixture properties for each one of the three simulations are presented in Table II.

The other inputs related to the mould characteristics and process related variables for the three simulations were the ones presented in Table III. 
Table I: Input data for the simulations.

\begin{tabular}{|l|c|c|}
\hline \multicolumn{1}{|c|}{ Input } & Value & Units \\
\hline Initial temperature* & 20.8 & ${ }^{\circ} \mathrm{C}$ \\
\hline Thermoplastic mass fraction & 0.5 & - \\
\hline Cork granules bulk density* & 66 & $\mathrm{~kg} / \mathrm{m}^{3}$ \\
\hline Thermoplastic powder bulk density* & 347 & $\mathrm{~kg} / \mathrm{m}^{3}$ \\
\hline Initial thickness* & 125 & $\mathrm{~mm}$ \\
\hline Final thickness* & 35 & $\mathrm{~mm}$ \\
\hline Cork density* & 138 & $\mathrm{~kg} / \mathrm{m}^{3}$ \\
\hline Thermoplastic density** & 950 & $\mathrm{~kg} / \mathrm{m}^{3}$ \\
\hline Cork specific heat & 2000 & $\mathrm{~J} / \mathrm{kg} \cdot \mathrm{K}$ \\
\hline Thermoplastic specific heat** & 2300 & $\mathrm{~J} / \mathrm{kg} \cdot \mathrm{K}$ \\
\hline Cork cell wall density [17] & 1150 & $\mathrm{~kg} / \mathrm{m}^{3}$ \\
\hline Thermoplastic thermal conductivity coefficient*** & 0.35 & $\mathrm{~W} / \mathrm{m} \cdot \mathrm{K}$ \\
\hline
\end{tabular}

*Data obtained by experimental tests; **Thermoplastic data

Table II: Mixture properties.

\begin{tabular}{|l|c|c|c|}
\hline \multicolumn{1}{|c|}{ Analysis } & $\mathbf{\# 1}$ & $\mathbf{\# 2}$ & $\mathbf{\# 3}$ \\
\hline Density $\left[\mathrm{kg} / \mathrm{m}^{3}\right]$ & 393 & 393 & 393 \\
\hline Thermal conductivity coefficient $[\mathrm{W} / \mathrm{m} \cdot \mathrm{K}]$ & 0.081 & $0.0002 T+0.0778$ & $0.0002 T+0.0778$ \\
\hline Specific heat $[\mathrm{J} / \mathrm{kg} \cdot \mathrm{K}]$ & 2153 & 2153 & $\begin{array}{c}2149, T<T_{s} \\
3211, T_{s} \leq T \leq T_{L} \\
2149, T>T_{L}\end{array}$ \\
\hline
\end{tabular}

Table III: Simulation input variables.

\begin{tabular}{|c|l|c|c|}
\cline { 2 - 4 } \multicolumn{1}{c|}{ Input } & Value & Units \\
\hline \multirow{4}{*}{$\begin{array}{c}\text { Mould propertie } \\
\text { (steel) }\end{array}$} & Density & 7400 & $\mathrm{~kg} / \mathrm{m}^{3}$ \\
\cline { 2 - 4 } & Specific heat & 400 & $\mathrm{~J} / \mathrm{kg} \cdot \mathrm{K}$ \\
\cline { 2 - 4 } & Thermal conductivity coefficient & 50 & $\mathrm{~W} / \mathrm{m} \cdot \mathrm{K}$ \\
\hline \multirow{4}{*}{ Process variables } & Mould thickness & 5 & $\mathrm{~mm}$ \\
\cline { 2 - 4 } & Mixture thickness & 35 & $\mathrm{~mm}$ \\
\cline { 2 - 4 } & Oven temperature & 140 & ${ }^{\circ} \mathrm{C}$ \\
\cline { 2 - 4 } & Heat transfer coefficient & 10 & $\mathrm{~W} / \mathrm{m}^{2} \cdot \mathrm{K}$ \\
\cline { 2 - 4 } & Initial temperature & 20.8 & ${ }^{\circ} \mathrm{C}$ \\
\hline
\end{tabular}

\subsection{Simulation results}

Assuming constant thermal properties, the obtained results for the temperature of the centre of the mixture throughout the process are presented in Fig. 6. The two different numerical methods employed presented very similar results, approximated to the experimental results. The results provided by the finite element analysis is also very close to the results from the finite volume method approach. However, in the second simulation (Fig. 7), the temperature results are higher compared to the first analysis. This is consistent with the fact that in the second analysis the thermal conductivity coefficient of the mixture increases with the value of temperature.

Comparing the simulation results with the experimental data is possible to verify some differences between the temperature profiles. In the centre of the mixture, the maximum difference between the experimental and simulation data is around $6{ }^{\circ} \mathrm{C}$ at half of the heating process. 


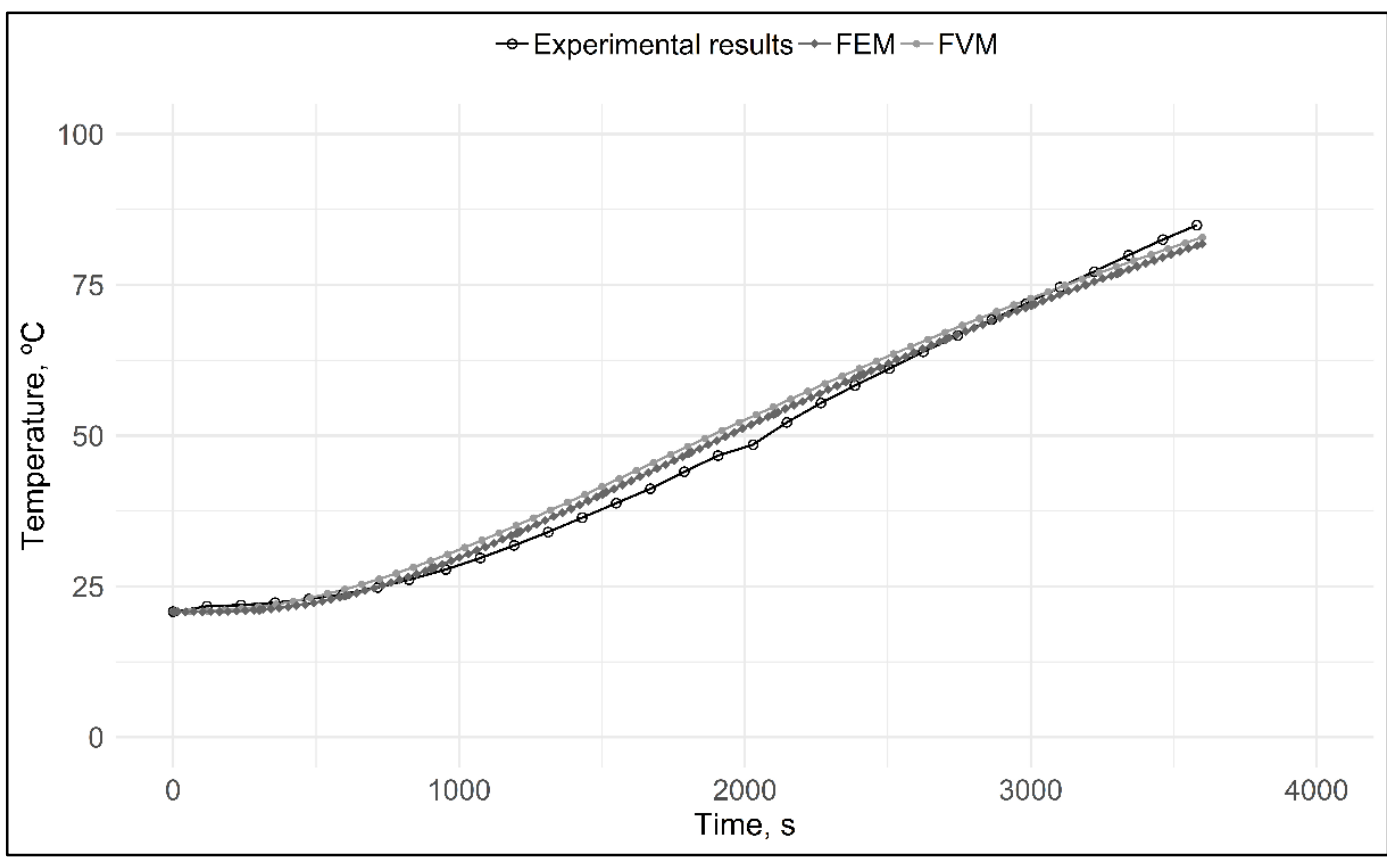

Figure 6: Centre temperature profile (simulation 1).

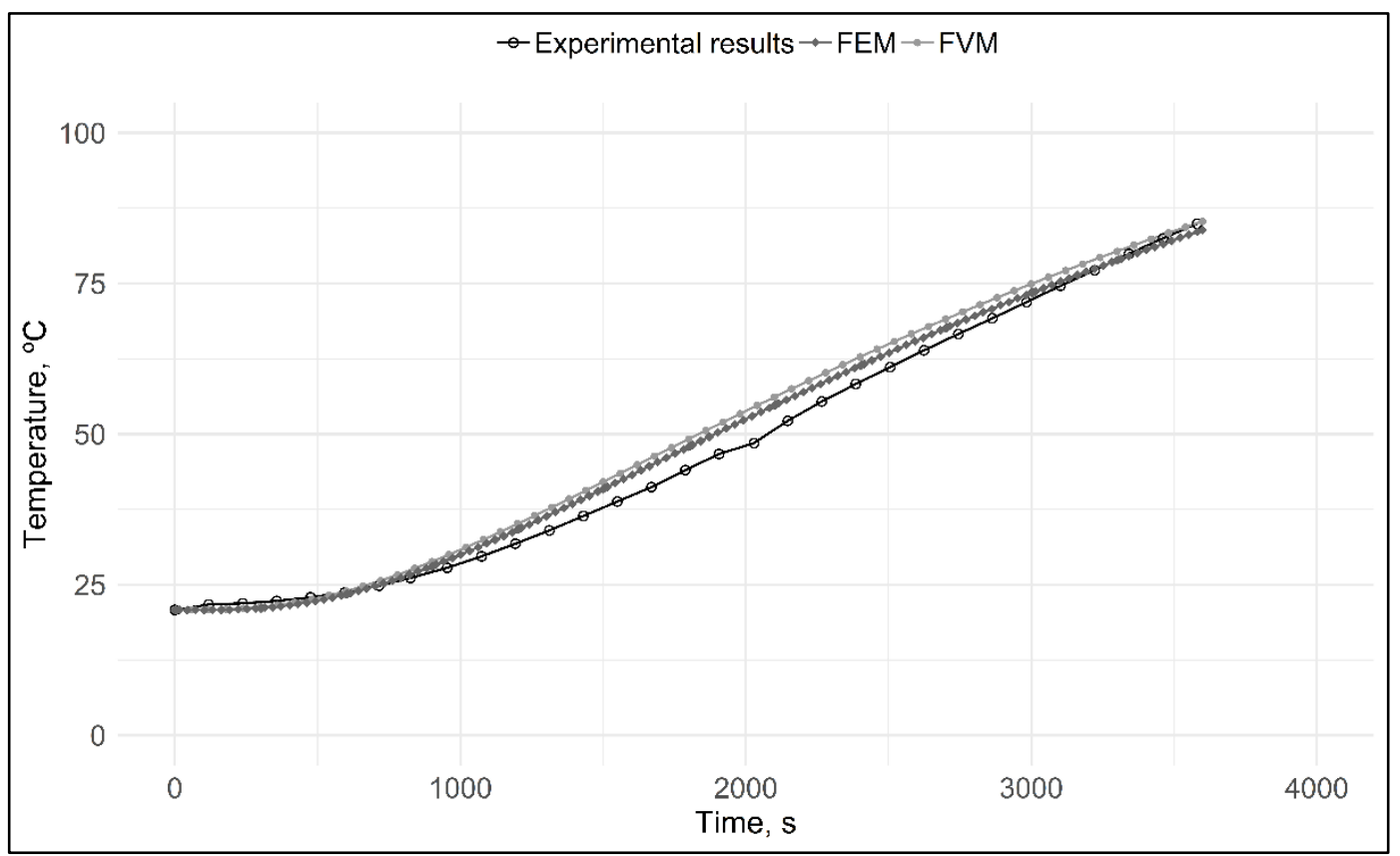

Figure 7: Centre temperature profile (simulation 2).

The temperature behaviour at the centre of the material obtained by the analysis that assumes a temperature dependence of thermal conductivity and specific heat (Fig. 8) shows some differences when compared with experimental data, with a maximum difference around $6^{\circ} \mathrm{C}$ at half of the heating process. Until reaching the thermoplastic melting stage, the behaviour is very close to the one predicted in the second analysis. However, with the increase of the specific heat of the mixture, a deceleration on the temperature of the material is noted when compared to the observed in the other analysis. 


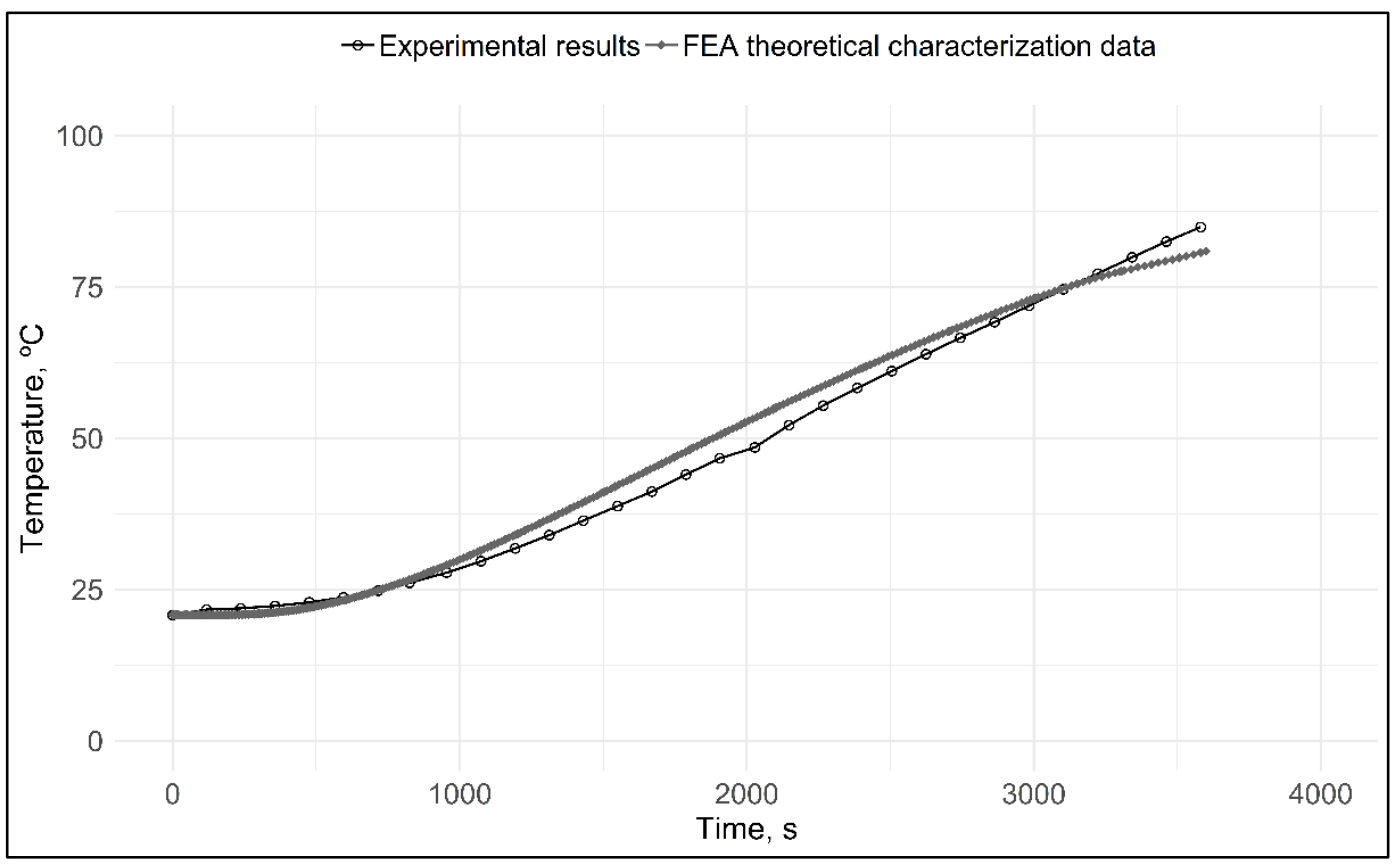

Figure 8: Centre temperature profile (simulation 3).

In the three cases (Fig. 9), the agglomeration at the centre of the material only starts around ten to five minutes before finalizing the heating process as it was observed in the experiments.

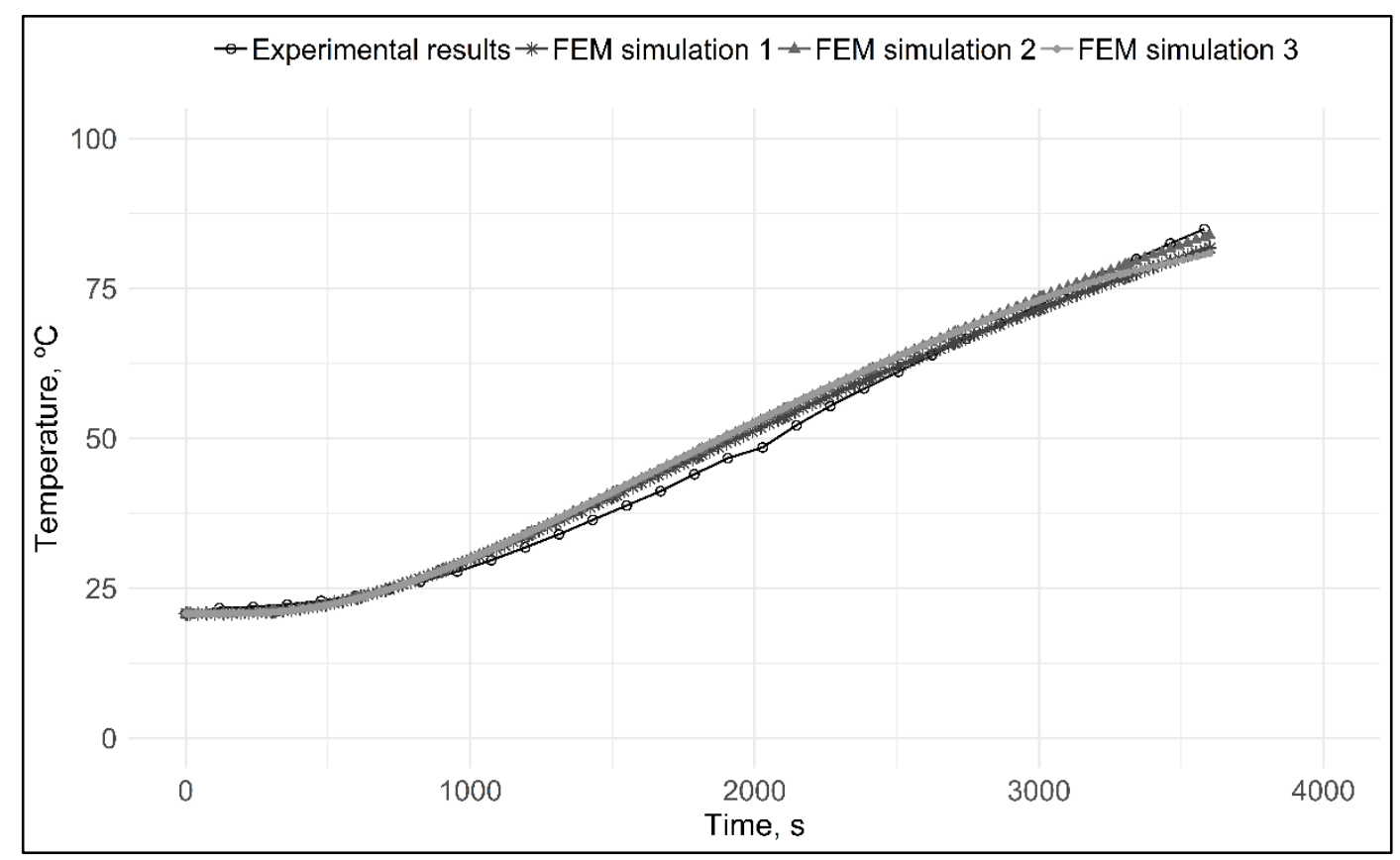

Figure 9: Centre temperature profile (all simulations).

The obtained differences between the experimental and simulations results can be explained by the combination of several factors. Some factors are related to the experimental setup like a possible displacement and delay from the thermocouple, or the opening of the oven that caused a decrease on the temperature inside during the first minutes of heating the mixture; other factors are related to the assumptions on the analysis. In terms of the material properties models, some assumptions can influence the results obtained like, for instance, considering the homogeneity of the mixture and the used data for the properties of the raw materials. Regarding the analysis, some of the deviations can be assigned to the simplicity of the analysis which 
considered as relevant only the heat flow in a single direction. In reality, it is necessary to consider the heat flow coming from the length and width directions although these can have less contribution to the final reached temperature comparing with the direction analysis. Other factors could be related to a thermal resistance existence between the mould surfaces and the mixture that was not considered, and the system initial temperature indicated for the analysis that might not correspond to the real situation. Although not considering these aspects - some of which are experimentally time-consuming and/or difficult to achieve - the developed model proved to be enough to simulate the heating process within a reasonable computation time.

\section{CONCLUSION}

The presented work demonstrated the application of an analytical model to predict the properties of a mixture used for the manufacturing of cork composite blocks. Based on experimental tests and literature values of the raw materials, density, thermal conductivity and specific heat of a mixture were determined. These data were applied in numerical analysis to evaluate the temperature evolution during the moulding process of cork composites. Several simulations, using two different numerical methods, were performed and compared with experimental information obtained using a thermocouple placed inside the centre of a mixture for processing. Due to the lack of information related to properties of the components of the mixture, the possibility of existing a thermal dependence on thermal conductivity or/and specific heat was evaluated.

The results from three simulations cases were in a close agreement although with a few exceptions on the middle and final part of the process. The maximum deviation obtained between the experimental and numerical analyses was $6{ }^{\circ} \mathrm{C}$, which could be acceptable due to the simplicity of the analysis and the experimental setup characteristics.

A prediction about the temperature evolution during a moulding process can be provided by the application of the methodology presented, allowing a time reduction regarding the search of optimal conditions to the produce different cork composites materials. Other analyses using different formulations can be considered to evaluate the capacity of the developed model. Other aspects related to the analysis, like moisture content and the inclusion of the length and width directions, can also be considered to improve the model. However, by adding more variables to the problem, more laboratory experiments and longer computation time will be required. This may not compensate for the differences regarding a simpler model such as the one developed.

\section{ACKNOWLEDGEMENT}

The authors are grateful to FCT - Fundação para a Ciência e Tecnologia who financially supported this work through scholarship SFRH/BD/136700/2018 and to Amorim Cork Composites for providing the materials and resources necessary to this study. This work has been supported by FCT - Fundação para a Ciência e Tecnologia within the R\&D Units Project Scope: UIDP/04077/2020 and UIDB/04077/2020.

\section{REFERENCES}

[1] Silva, S. P.; Sabino, M. A.; Fernandes, E. M.; Correlo, V. M.; Boesel, L. F.; Reis, R. L. (2005). Cork: properties, capabilities and applications, International Materials Reviews, Vol. 50, No. 6, 345-365, doi:10.1179/174328005X41168

[2] Soares, B.; Reis, L.; Sousa, L. (2011). Cork composites and their role in sustainable development, Procedia Engineering, Vol. 10, 3214-3219, doi:10.1016/j.proeng.2011.04.531

[3] Gil, L. (2009). Cork composites: a review, Materials, Vol. 2, No. 3, 776-789, doi:10.3390/ ma2030776

[4] Gil, L. (2015). New cork-based materials and applications, Materials, Vol. 8, No. 2, 625-637, doi: $\underline{10.3390 / \mathrm{ma} 8020625}$ 
[5] Fernandes, E. M.; Pires, R. A.; Reis, R. L. (2017). Cork biomass biocomposites: Lightweight and sustainable materials, Jawaid, M.; Tahir, P. M.; Saba, N.(Eds.), Lignocellulosic Fibre and BiomassBased Composite Materials, Woodhead Publishing, Cambridge, 365-385, doi:10.1016/B978-0-08100959-8.00017-2

[6] Trende, A.; Åström, B. T. (2002). Heat transfer in compression molding of thermoplastic composite laminates and sandwich panels, Journal of Thermoplastic Composite Materials, Vol. 15, No. 1, 43-63, doi:10.1106/089270502022862

[7] Carvalho, L. M. H.; Costa, M. R. N.; Costa, C. A. V. (2003). A global model for the hot-pressing of MDF, Wood Science and Technology, Vol. 37, No. 3-4, 241-258, doi:10.1007/s00226-0030170-Z

[8] Zombori, B. G.; Kamke, F. A.; Watson, L. T. (2003). Simulation of the internal conditions during the hot-pressing process, Wood and Fiber Science, Vol. 35, No. 1, 2-23

[9] Behzad, T.; Sain, M. (2007). Finite element modeling of polymer curing in natural fiber reinforced composites, Composites Science and Technology, Vol. 67, No. 7-8, 1666-1673, doi:10.1016/ j.compscitech.2006.06.021

[10] Ternik, P.; Rudolf, R. (2016). Numerical analysis of continuous casting of NiTi shape memory alloy, International Journal of Simulation Modelling, Vol. 15, No. 3, 522-531, doi:10.2507/IJSIMM15(3)11.360

[11] Mrozek, K. (2018). Simulation study of induction heating of multi-metallic injection moulds, International Journal of Simulation Modelling, Vol. 17, No. 2, 220-230, doi:10.2507/ IJSIMM17(2)415

[12] Ren, M.; Wang, Q.; Cong, J.; Chang, X. (2018). Study of one-dimensional cure simulation applicable conditions for thick laminates and its comparison with three-dimensional simulation, Science and Engineering of Composite Materials, Vol. 25, No. 6, 1197-1204, doi:10.1515/secm2017-0244

[13] Gao, Y.; Xu, C.; Yang, L.; Wang, B. (2019). Simulation study on the formation of PLGA microstructure using hot-pressing method, International Journal of Simulation Modelling, Vol. 18, No. 4, 643-653, doi:10.2507/IJSIMM18(4)496

[14] Miler, D.; Škec, S.; Katana, B.; Žeželj, D. (2019). An experimental study of composite plain bearings: the influence of clearance on friction coefficient and temperature, Strojniski vestnik Journal of Mechanical Engineering, Vol. 65, No. 10, 547-556, doi:10.5545/sv-jme.2019.6108

[15] Alawadhi, E. M. (2009). Finite Element Simulations Using ANSYS, CRC Press, Boca Raton, doi: $10.1201 / 9781439801611$

[16] EN 1995-1-2. (2004). Eurocode 5: Design of timber structures - Part 1-2: General - Structural fire design, European Committee for Standardization, Brussels

[17] Gibson, L. J.; Easterling, K. E.; Ashby, M. F. (1981). The structure and mechanics of cork, Proceedings of the Royal Society A: Mathematical, Physical and Engineering Sciences, Vol. 377, No. 1769, 99-117, doi:10.1098/rspa.1981.0117 